\title{
Effects of Annealing and Deformation on Sagging Resistance of a Hot-Rolled, Four-Layered Al Alloy Clad Sheet
}

\author{
Minglong Kang $\mathbb{D}^{1},{ }^{1}$ Li Zhou $\mathbb{D}^{2},{ }^{2}$ Yunlai Deng, ${ }^{3}$ and Jinqin Lei ${ }^{4}$ \\ ${ }^{1}$ Light Alloys Research Institute, Central South University, Changsha 410083, China \\ ${ }^{2}$ Hunan Engineering Research Center of New Energy Vehicle Lightweight, Hunan Institute of Engineering, \\ Xiangtan 411101, China \\ ${ }^{3}$ Key Laboratory of Nonferrous Materials Science and Engineering, Ministry of Education, Central South University, \\ Changsha 410083, China \\ ${ }^{4}$ China Northeast Light Alloy Co. Ltd., Harbin 150060, China
}

Correspondence should be addressed to Li Zhou; zhoulina.0401@163.com

Received 14 October 2020; Accepted 10 May 2021; Published 24 May 2021

Academic Editor: Patrice Berthod

Copyright (c) 2021 Minglong Kang et al. This is an open access article distributed under the Creative Commons Attribution License, which permits unrestricted use, distribution, and reproduction in any medium, provided the original work is properly cited.

\begin{abstract}
Multilayer brazeable aluminum alloy sheet is prone to collapse during high-temperature brazing process. The sagging resistance of the aluminum composite sheet needs to be further improved for quality control. Effects of annealing and rate of reduction on sagging resistance, microstructure, and Si diffusion of a hot-rolled, four-layered Al clad sheet (4343/3003/6111/3003) were investigated by means of a sagging device, OM, SEM, and TEM. Results showed that once annealed at $360^{\circ} \mathrm{C}$, the sagging distance was increased from 3 to $15.7 \mathrm{~mm}$ as the reduction rate changed from $10 \%$ to $40 \%$. By increasing annealing temperature to $410^{\circ} \mathrm{C}$, those were changed from 3.1 to $20.8 \mathrm{~mm}$ accordingly. At $360^{\circ} \mathrm{C} / 40 \%$ and $410^{\circ} \mathrm{C} / 40 \%$, specimens exhibited weak sagging resistance, whereas fine recrystallized grains were formed in the core promoting Si penetration along grain boundaries. While the specimens were treated at $360^{\circ} \mathrm{C} / 10 \%$ and $410^{\circ} \mathrm{C} / 10 \%$, better sagging resistance was observed due to the formation of coarse recrystallized grains that can suppress erosion of $\mathrm{Si}$. At the same reduction rate, the sagging resistance was higher for the sample annealed at a lower temperature as more precipitates appeared in the core $\left(\right.$ at $\left.360^{\circ} \mathrm{C}\right)$, thus leading to an increase in strength.
\end{abstract}

\section{Introduction}

Composed of support layer (core layer) and brazing layer (clad layer), multilayer aluminum brazing sheets have been widely used in heat exchanger and honeycomb sandwich structure [1] due to their low density, high thermal conductivity, and excellent corrosion resistance [2-5]. In order to reduce the weight of automotive parts and cut down production cost of the heat exchanger, the thickness of the $\mathrm{Al}$ brazing sheet has to be decreased [6]. During the brazing cycle, a thin clad-/core-layered sheet needs to endure a high temperature (around $580^{\circ} \mathrm{C}$ to $610^{\circ} \mathrm{C}$ ) under pressure, which may cause collapse $[3,4]$. Consequently, its high-temperature mechanical strength, or sagging resistance, has to be increased and it should be higher than the threshold for collapse $[4,7]$.
To solve the high-temperature collapse of aluminum composite sheets and improve their high-temperature sagging resistance, many research works have been conducted with focus on the influence of brazing temperature, microstructure, and Si diffusion on the sagging resistance of aluminum composite sheets during the thermal brazing cycle. For example, Qin et al. [8] observed that the value of sagging of the brazed foil sheet had undergone two stages of change as a function of temperature, and the sagging was attributed to dissolution of precipitates and softening of elastic modulus as a function of brazing temperature. Lee et al. $[2,3]$ studied the sagging behavior of three-layered (Al$\mathrm{Si} / \mathrm{Al}-\mathrm{Mn}-\mathrm{Zn} / \mathrm{Al}-\mathrm{Si}$ ) clad sheets and found that coarse recrystallized grains can improve sagging resistance. This type of microstructure can be obtained by controlling the 
rate of cold-rolling reduction and applying an intermediate annealing temperature. Yoon et al. [7] reported the brazeability of the three-layered (4343/3003/4343) aluminum clad sheet. Fine recrystallized grains were formed in the core during the brazing process, which promotes filler penetration along grain boundaries and increases the erosion area, thereby leading to weak sagging resistance. On the contrary, specimens with coarse recrystallized grains in the core exhibited excellent sagging resistance with suppressed erosion. Zhao et al. [9] investigated the effect of an intermediate annealing system on the sagging resistance of the three-layered (4343/3003/4343) aluminum composite sheet. Research indicated that abundant Si penetrated into the core layer and accelerated diffusion, which was the primary reason for the lower sagging resistance. Tang et al. [10] and Liu et al. [11] reported stages of sagging behavior of threelayered (AA4343/AA3003/AA4343) aluminum-clad foil. During the brazing process, they found that coarse grains formed under appropriate processing parameters would help improve sagging resistance. Although those early works have obtained numerous valuable results, mostly concentrated on the brazing process, microstructure evolution, the effect of precipitates on recrystallization, and so on, their explanations were not thorough and sufficient. Qin et al. discontinued the study of sagging behavior at a high temperature, where the effect of dispersoids has to be taken into consideration on sagging deformation [8].

Most studies have focused on the fabrication and brazeability of the three-layered (4343/3003/4343) aluminum clad sheet, with 3003 as the main core alloy. In order to improve the sagging resistance of aluminum brazing sheets, developing new core alloys and their corresponding sagging mechanism is in need. Recently, a four-layered (4343/3003/ $6111 / 3003$ ) Al sheet, with different core alloys, was suggested to facilitate the desired sagging resistance [12]. Compared with the three-layered brazing composite board, the newly developed four-layered (4343/3003/6111/3003) Al sheet has higher strength (increased by 50\%). The outer layers of the newly developed four-layered alloy are 4343 and 3003, containing one middle layer of 3003 and one inner layer of 6111. 4343 is the filler material that melts into solder during high-temperature brazing. The second layer 3003 protects the core material 6111 from corrosion and reduces the diffusion of $\mathrm{Si}$ atoms to the core layer during brazing. 3003 acts as a clad material, serves as a sacrificial anode, and protects the core material from corrosion. 6111 is the core and acts as a support layer. For this four-layer design, defects (such as collapse and lodging) during the brazing process primarily depend on the core layer.

In this work, effects of annealing and rate of reduction on sagging resistance, microstructure, and Si diffusion of a hotrolled, four-layered (4343/3003/6111/3003) Al clad sheet will be investigated by means of a sagging device (electronic universal testing machine) OM, SEM, and TEM. The objective of this paper is to combine and analyze data obtained from experiments to establish relationships among intermediate annealing, rolling deformation, and sagging resistance of the brazing sheet. The main purpose is to provide a solid theoretical foundation for the development of the composite aluminum clad sheet with high sagging resistance.

\section{Materials and Methods}

2.1. Material Preparation. Hot-rolled, four-layered (4343/ $3003 / 6111 / 3003$ ) Al clad sheet of $6 \mathrm{~mm}$ thickness was fabricated by Northeast Light Alloy Corporation, China. First, ingots of 6111,4343 , and 3003 were sliced into a sheet of what thickness by milling both surfaces, homogenizing at $550^{\circ} \mathrm{C}$, and holding for $30 \mathrm{~h}$. Second, those sheets were stacked up together according to order of 4343/3003/6111/ 3003; the cladding ratio (the cladding ratio here is referred to the thickness of single-sided layer as a percentage of the total thickness) is controlled in the order of $10 \%, 5 \%, 77 \%$, and $8 \%$. Then, the sheets were welded by riveting and then heated to $450^{\circ} \mathrm{C}-480^{\circ} \mathrm{C}$; the hot-rolled slabs are obtained by rolling, leveling, and shearing.

The clad and the core layers of the interface are flat and leveled, with uniform thickness and good shape, and meet the requirements of usage. The layers 6111 and 4343 serve as the core layer and the cladding layer, respectively. The specific ingredients of these alloys are shown in Table 1 . The thickness of each layer of the clad sheet, 4343/3003/6111/ 3003 , is shown in Figure 1. The cladding ratio (4343/3003/ $6111 / 3003$ ) is $10 \%, 5 \%, 77 \%$, and $8 \%$ in sequence.

During the manufacturing of heat exchangers, once brazed at high temperature, the filler will be completely melted, and the melted filler will be constantly infiltrated, expanded, and solidified later at the gap between radiating fins and composite tubes to form brazed joints rich in Al-Si eutectic composition. Consequently, radiating fins and composite tubes can be metallurgically bonded together.

2.2. Experimental Procedure. The schematic illustration of the experiment is shown in Figure 2. The $6 \mathrm{~mm} \mathrm{Al} \mathrm{clad} \mathrm{sheet}$ was cold-rolled to various thicknesses at different rates of reduction $(10 \%, 15 \%, 20 \%, 25 \%, 30 \%$, and $40 \%)$. After intermediate annealing at $360^{\circ} \mathrm{C}$ or $410^{\circ} \mathrm{C}$ for $2 \mathrm{~h}$, the clad sheets were cold-rolled to a thickness of $1 \mathrm{~mm}$ and then kept at $610^{\circ} \mathrm{C}$ for $10 \mathrm{~min}$ to simulate the brazing process. First, the resistance furnace was heated to $610^{\circ} \mathrm{C}$ and kept stable for $20 \mathrm{~min}$ in order to eliminate the influence of the heating rate and holding time, and then the assembled test device (one sample) was moved into the furnace steadily. The temperature fluctuation was controlled within $\pm 3^{\circ} \mathrm{C}$ during simulation, and the sample was held there for $10 \mathrm{~min}$, before taking it out smoothly. The entire process of the simulation was protected by the flow of nitrogen.

\subsection{Test Method}

2.3.1. Tensile Test Analysis. The $6 \mathrm{~mm} \mathrm{Al} \mathrm{clad} \mathrm{sheet} \mathrm{was}$ annealed at $300^{\circ} \mathrm{C}$ to $500^{\circ} \mathrm{C}$ for $2 \mathrm{~h}$. According to $\mathrm{GB} / \mathrm{T} 228$ 2002, tensile specimens were obtained by wire-electrode cutting after annealing. The shape and size of the sample are shown in Figure 3. The yield strength, tensile strength, and elongation of the tensile sample were measured on a 
TABLE 1: Chemical compositions of 4343/3003/6111/3003 (mass fraction, \%).

\begin{tabular}{|c|c|c|c|c|c|c|c|c|}
\hline \multirow{2}{*}{ Material } & \multicolumn{8}{|c|}{ Wt. (mass fraction, \%) } \\
\hline & $\mathrm{Si}$ & $\mathrm{Fe}$ & $\mathrm{Cu}$ & $\mathrm{Mn}$ & $\mathrm{Mg}$ & $\mathrm{Zn}$ & $\mathrm{Ti}$ & $\mathrm{Al}$ \\
\hline 4343 & $7.8-8.2$ & $0.15-0.30$ & 0.05 & 0.05 & 0.03 & - & - & Bal. \\
\hline 3003 & 0.6 & 0.7 & $0.05-0.20$ & $1.0-1.5$ & - & 0.10 & - & Bal. \\
\hline 6111 & $0.7-1.1$ & $<0.4$ & $0.5-1.0$ & $0.10-0.45$ & $0.50-1.0$ & $<0.15$ & $<0.10$ & Bal. \\
\hline
\end{tabular}

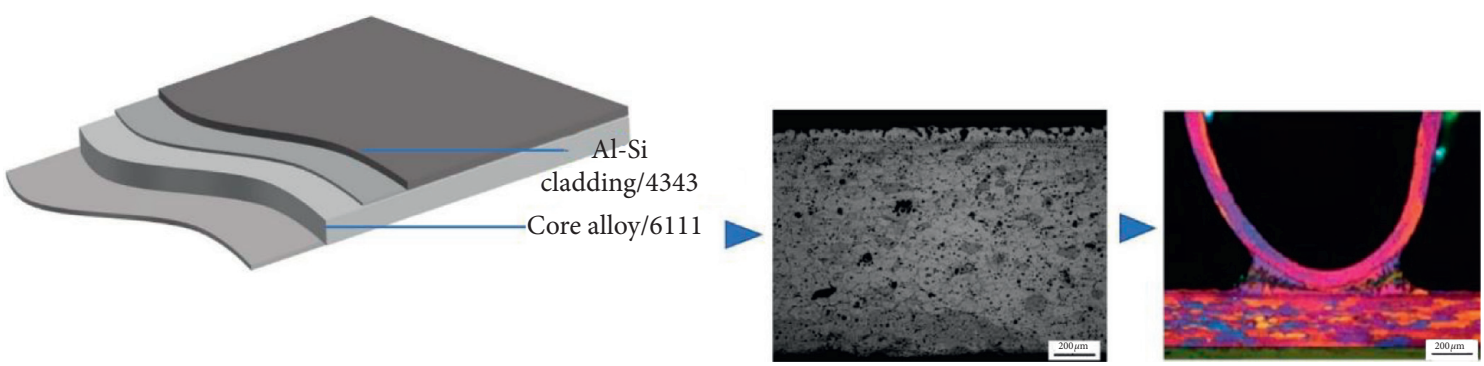

Figure 1: Brazing process of aluminum clad sheets with Al-Mg-Si core alloy and Al-Si clad layers.

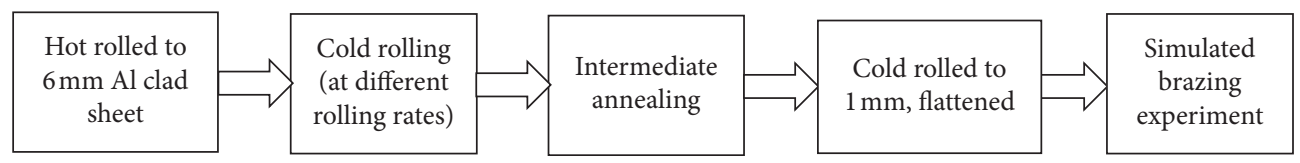

Figure 2: Schematic illustration of brazing simulation.

CSS-44100 electronic universal testing machine at the rate of $9 \mathrm{~mm} / \mathrm{min}$

The tensile specimens, as shown in Figure 3, were obtained from a four-layered $\mathrm{Al}$ clad sheet after simulation. Tensile testing was conducted at room temperature. Three specimens were prepared for each experiment with the average value being reported in the text.

2.3.2. Sagging Resistance Test. According to the standard of the Japan Cryogenic Committee $[4,13]$, the sagging resistance was tested to evaluate the brazeability of those clad sheets. The sagging test device and the distance of sagging are shown in Figures 4(a) and 4(b), respectively. The specimens were taken parallel to the rolling direction, with a length and width of $55 \mathrm{~mm}$ and $22 \mathrm{~mm}$, respectively, as shown in Figure 4(a). One end of the specimens was fixed, and the other end of $50 \mathrm{~mm}$ length was free. After the abovementioned simulated brazing, the vertical height difference of the test specimens before and after the experiment was tested and then the sagging value was calculated as shown in Figure 4(b). The sagging distance was defined as the deflection of the free end after brazing. A smaller sagging value of the specimen indicates better sagging resistance [14].

2.3.3. Metallographic Analysis. The samples after the sagging test were cut into small pieces of $20 \mathrm{~mm}$ in length and inlaid into a round ball shape. The specimens were successively ground with $80 \#-, 320 \#-, 800 \#-$, and $1200 \#$-grit SiC papers. A special rough and fine polishing cloth was used until the surface of the sample was bright without scratches. The polished samples were electropolished in a solution of perchloric acid + alcohol (1:9) at a voltage/current of $12 \mathrm{v} /$ $0.2 \mathrm{~mA}$ for $30-60 \mathrm{~s}$. Electrolytic polishing was performed at $-30^{\circ} \mathrm{C}$ in liquid nitrogen to remove the stress on the surface and to obtain highly cleaned and brightly polished samples. The electropolished samples were used for metallographic observation. A simple version of the electrolytic polishing device is shown in Figure 5.

2.3.4. Scanning Electron Microscope Analysis. Microstructure observation and EDS analysis of the samples were performed using an FEI-Quanta scanning electron microscope at an accelerating voltage of $20 \mathrm{kV}$. The specimens were first coarsely ground with $80 \#, 320 \#$, and $800 \#$ water matte sandpapers and then finely ground with 400\#, $800 \#$, and 1200\# metallographic sandpapers, prior to being mechanically polished to achieve a bright surface. Finally, the polished samples were soaked in alcohol and shaken for 5 min inside a KQ-700GVDV ultrasonic machine. Samples were washed with distilled water and blow-dried for further examinations.

2.3.5. Transmission Electron Microscope Analysis. The microstructures of the samples after the sagging test were observed on a Tecnai G220 transmission electron microscope at an acceleration voltage of $200 \mathrm{kV}$. The TEM film specimens were first ground to $0.08-0.1 \mathrm{~mm}$ with a $800 \#$ water sanding paper, punched into a small disc at a diameter of $3 \mathrm{~mm}$, and thinned with double-jet on the MT-PI-type double-jet electrolytic thinning instrument. Double spray liquid was a mixed solution of $25 \% \mathrm{HNO}_{3}+75 \% \mathrm{CH}_{3} \mathrm{OH}$ (volume fraction). When double spraying, 15-25 $\mathrm{V}$ was used 


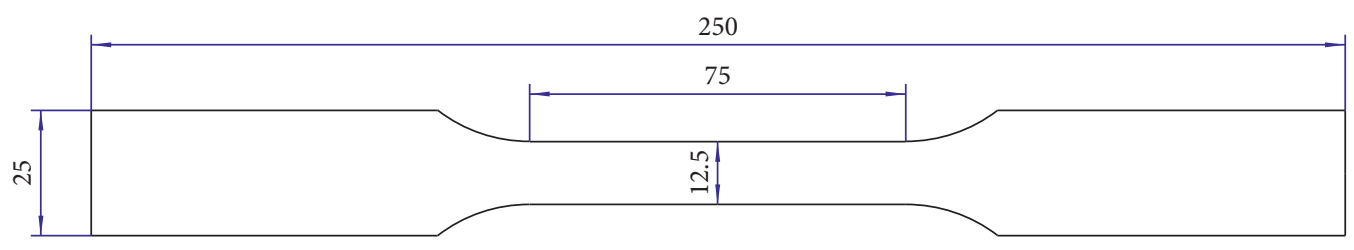

FIgURE 3: The drawing of tensile test specimen (unit: $\mathrm{mm}$ ).

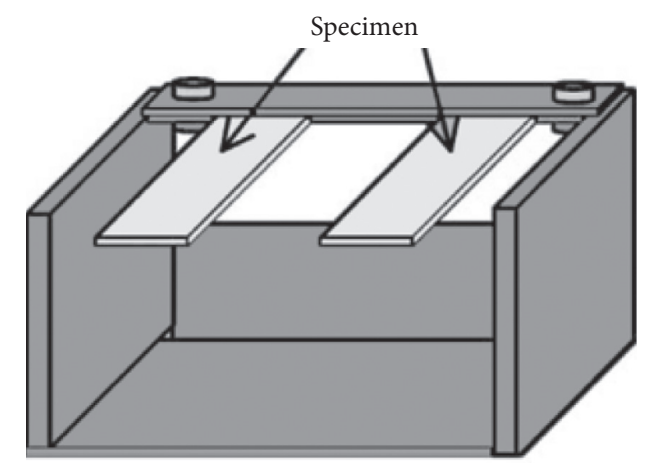

(a)

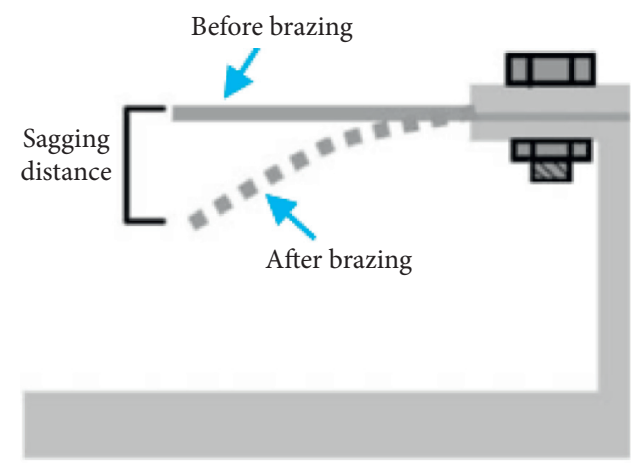

(b)

FIGURE 4: Schematic illustration of sagging setup.

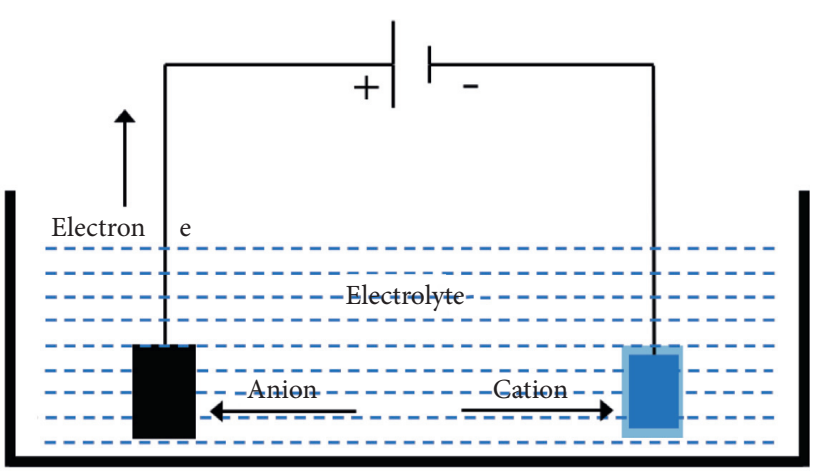

FIGURE 5: Electropolishing setup.

as working voltage, while the current was controlled at around $70 \mathrm{~mA}$ and cooled to $-20^{\circ} \mathrm{C}$ to $-35^{\circ} \mathrm{C}$ with liquid nitrogen. The sample should be cleaned with alcohol at least $30 \mathrm{~min}$ after double spraying.

\section{Results and Discussion}

3.1. Effect of Annealing Temperature on the Performance of Al Alloy Clad Sheets. Figure 6 shows the tensile property of hotrolled, four-layered aluminum alloy clad sheets as a function of temperature. The temperature ranges from $300^{\circ} \mathrm{C}$ to $500^{\circ} \mathrm{C}$ (holding for $2 \mathrm{~h}$ ). As the annealing temperature increases, tensile strength and yield strength decrease slightly, while elongation increases first and then decreases. Above $360^{\circ} \mathrm{C}$, tensile strength changes slightly; elongation reaches the highest at $410^{\circ} \mathrm{C}$ and then starts to decrease. After hot and cold rolling, the $\mathrm{Al}$ alloy clad sheets could store a large amount of deformation energy that can cause serious work hardening. Unannealing composite aluminum foil had formed very small grains after brazing; sagging resistance and plasticity were very poor. Generally, complete intermediate annealing should be required to improve microstructure and enhance performance. Lower temperature or shorter time results in insufficient annealing; higher temperature or longer time has a negative effect on sagging resistance. A suitable annealing system is then guaranteed for suitable sagging resistance of aluminum sheets.

3.2. Effect of Temperature and Rate of Reduction on Sagging. Microstructure of nonbrazed (4343/3003/6111/3003) Al clad sheet rolled to $30 \%$ and annealed at $410^{\circ} \mathrm{C}$ is shown in Figure 7. The interface between cladding layers $(4343 / 3003$ and 3003) and the core layer (6111) is clearly distinguishable. Uniform distributed Si particles (indicated by an arrow) can be found in the layer of 4343 .

Sagging tests were carried out at different fabricating conditions. Sagging behaviors are recorded and presented in Figures 8 and 9 . As the rate of reduction changed from $10 \%$ to $40 \%$, the sagging distance increased accordingly for those clad sheets annealed at $360^{\circ} \mathrm{C}$ and $410^{\circ} \mathrm{C}$. In other words, sagging resistance was under deterioration at a higher rate of reduction. For instance, when specimens annealed at $360^{\circ} \mathrm{C}$ and $410^{\circ} \mathrm{C}$, small sagging distances $(3$ and $3.1 \mathrm{~mm}$, respectively) were measured at a reduction (cold rolling) rate of $10 \%$. Those figures jumped to 15.7 and $20.8 \mathrm{~mm}$, respectively, at $40 \%$. Room temperature yield strengths of the brazed four-layered Al alloy clad sheets (shown in Figure 10) under different process conditions are consistent with their sagging behaviors.

3.3. Effects of Rate of Reduction on Microstructure and Sagging Resistance upon Brazing. The melted filler alloy could erode the core material along the grain boundary during brazing, 


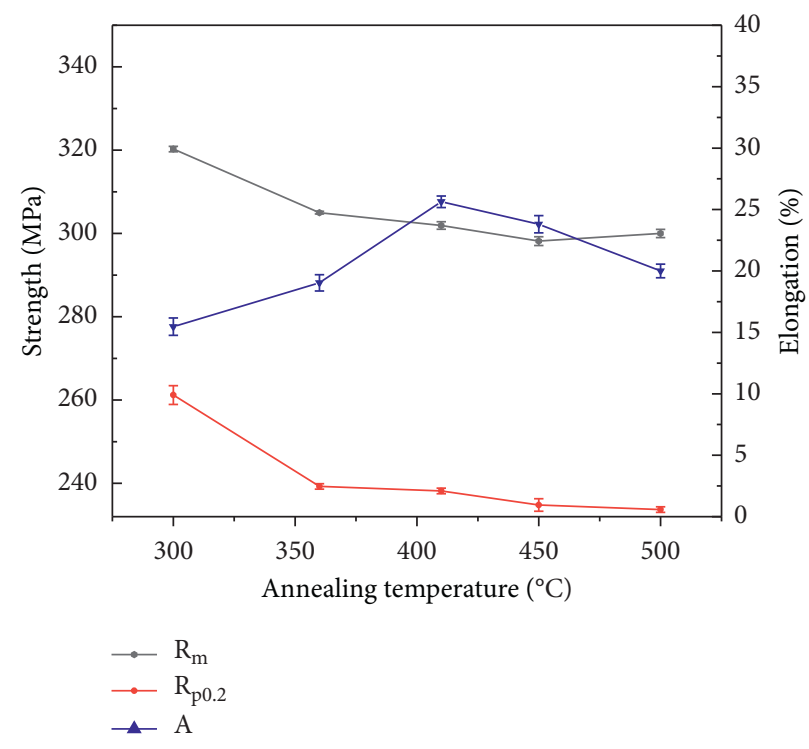

FIGURE 6: Relationship between mechanical properties of hot-rolled, four-layered aluminum alloy clad sheets and temperature (holding for $2 \mathrm{~h} ; \mathrm{R}_{\mathrm{m}}, \mathrm{R}_{\mathrm{p} 0.2}$, and A represent tensile strength, yield strength, and percentage elongation, respectively).

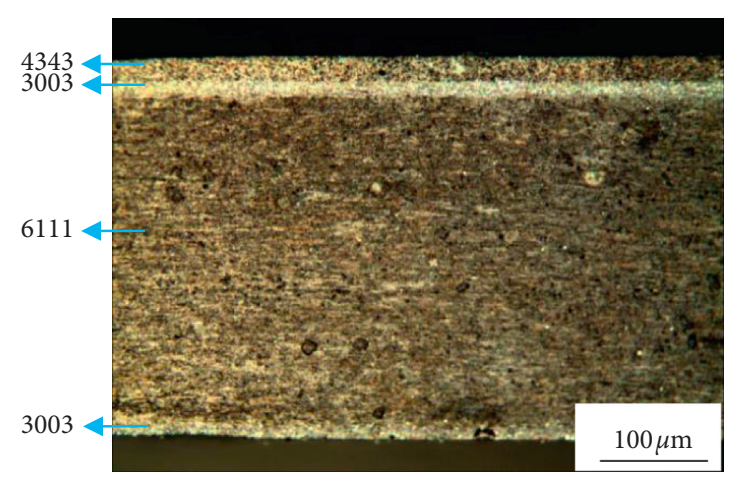

(a)

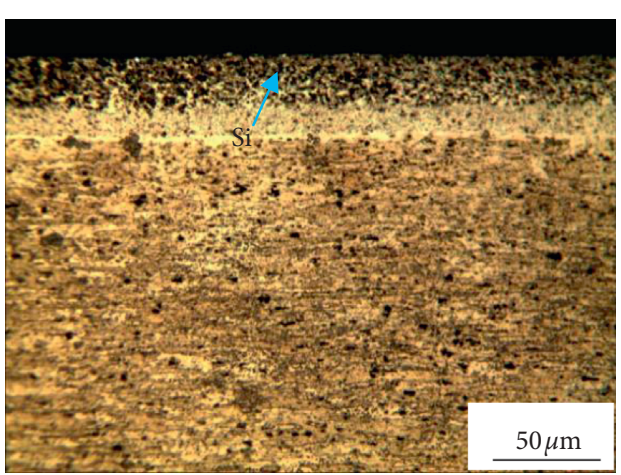

(b)

Figure 7: Microstructures of the $4343 / 3003 / 6111 / 3003$ clad sheets that were rolled to $30 \%$ and annealed at $410^{\circ} \mathrm{C}$ : (a) $100 \mathrm{x}$ and (b) $200 \mathrm{x}$.

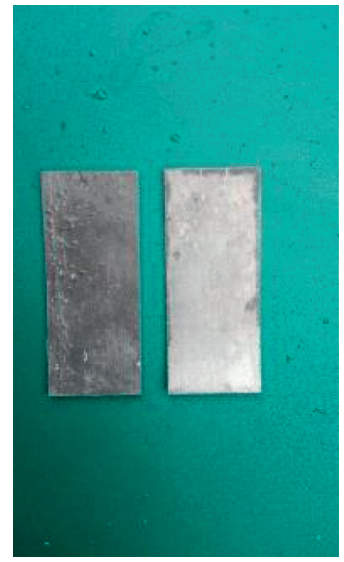

(a)

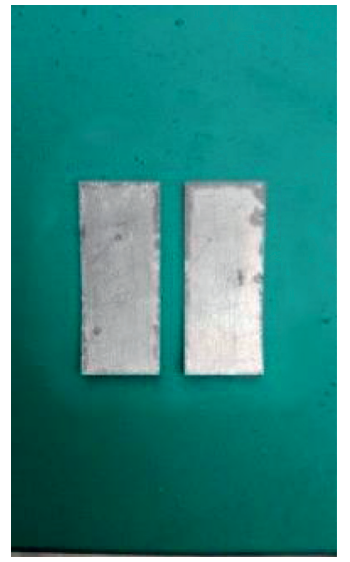

(b)

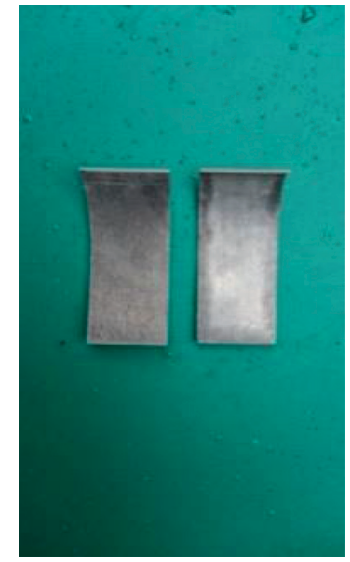

(c)

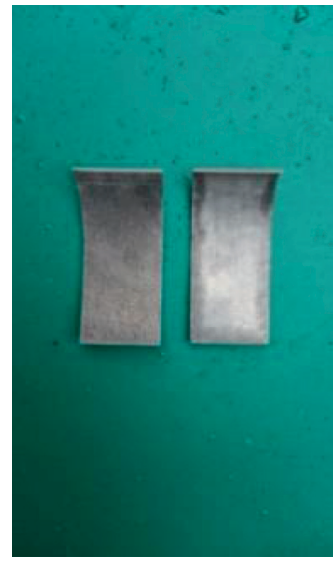

(d)

Figure 8: Brazed $\left(4343 / 3003 / 6111 / 3003\right.$ ) clad sheets annealed at $410^{\circ} \mathrm{C}$ (left) $/ 360^{\circ} \mathrm{C}$ (right) as function of rate of reduction: (a) $10 \%$, (b) $20 \%$, (c) $30 \%$, and (d) $40 \%$. 


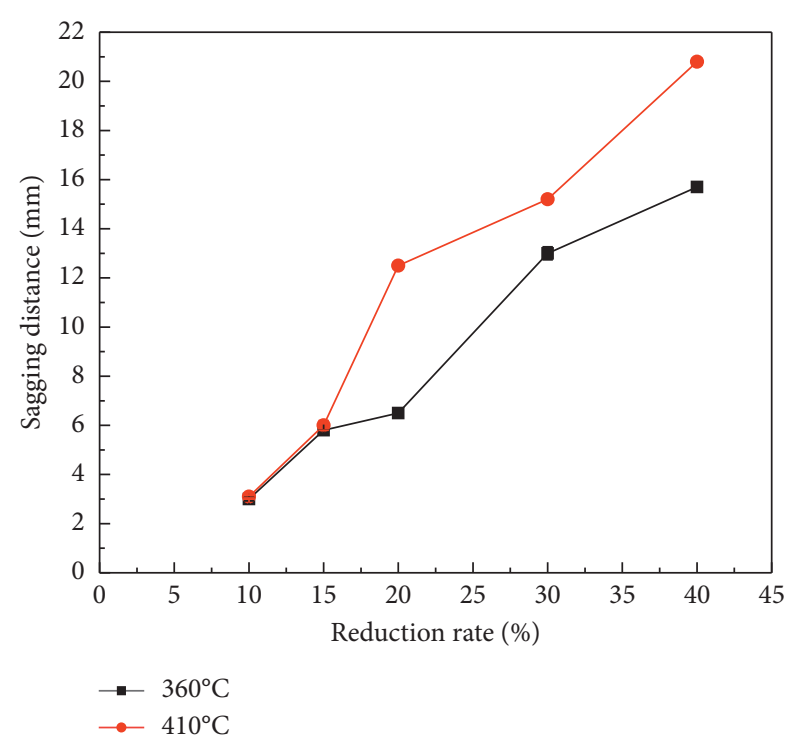

Figure 9: Sagging distance as a function of the rate of reduction after brazing.

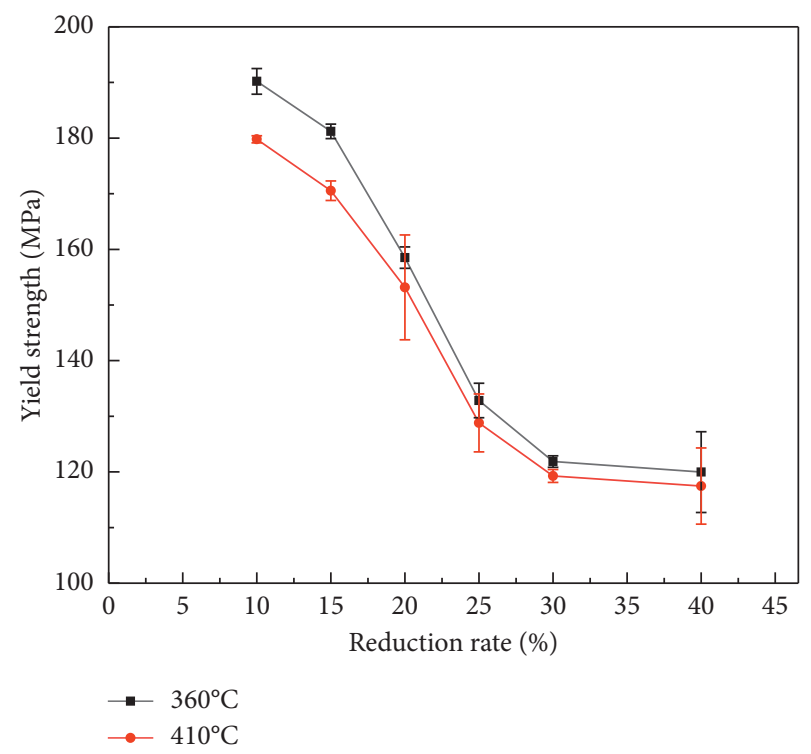

FIGURE 10: Yield strength versus rate of reduction upon brazing.

which is the main reason for the collapse. One effective way to mitigate collapse is to reduce grain boundaries during brazing. The grain size of the core material is primarily determined by the rate of reduction and affects the progress of erosion and the degree of collapse.

Microstructures of brazed Al cladding sheets were observed using OM and SEM with typical results shown in Figures 11-14, respectively. For specimens annealed at $360^{\circ} \mathrm{C}$, the average erosion depth ratio of $\mathrm{Al}-\mathrm{Si}$ increased from $7.5 \%$ to $14.3 \%$, associating with the rate of reduction changed from $10 \%$ to $40 \%$. Coarse recrystallized grains formed in the core were transformed into fine grains, and their average grain size shown gradually decreased from 156 to $55 \mu \mathrm{m}$. Similar trends were observed for specimens annealed at $410^{\circ} \mathrm{C}$, that is, the average erosion depth ratio increased from $11.9 \%$ to $18.3 \%$ with grain size decreased from 120 to $42 \mu \mathrm{m}$ as the rate of reduction increased from $10 \%$ to $40 \%$.

The microstructures observed indicate a close relationship with the sagging behavior of the Al cladding sheets. As indicated by the results in Figures 9 and 11-14, for specimens annealed at both $360^{\circ} \mathrm{C}$ and $410^{\circ} \mathrm{C}$, with the reduction rate increased from $10 \%$ to $40 \%$, the sagging distance of the Al clad sheets increased as well, so did the eroded areas by $\mathrm{Si}$ penetration. Also, the size of the recrystallized grains formed in the core decreased gradually. Si content in the core would affect the sagging resistance. Silicon diffuses into the core causing a negative impact on sagging resistance $[13,15]$. Once the Al clad sheets annealed at $410^{\circ} \mathrm{C}$ and cold rolled to $40 \%$, they showed less sagging resistance (sagging distance of $20.8 \mathrm{~mm}$ ) and erosion by Si went deep into the core with an average depth ratio of $18.3 \%$. By contrast, once the $\mathrm{Al}$ clad sheets were subjected to cold rolling of $10 \%$ and annealing at $360^{\circ} \mathrm{C}$, their sagging distance was only $3 \mathrm{~mm}$ with a low average erosion depth ratio of $7.5 \%$. According to those microstructures, recrystallized grains in the core are much finer at a higher cold-rolling reduction rate, which leads to an increase in grain boundaries during brazing. This is because the stored deformation energy in Al cladding sheets increased with reduction rate. Nucleation was promoted during annealing and thus formed more grains. Interface defect existing in the substructure grain boundary is a high-speed channel for Si element in the filler to diffuse to the core layer. Fine grains provide high-density diffusion channels compared with coarse strip grains $[16,17]$. As shown at the yellow line in Figures 13 and 14, during the brazing process, Si diffuses along the grain boundary and forms Al-Si eutectic phase at the grain boundary. The melting temperature of the Al-Si eutectic phase is $577^{\circ} \mathrm{C}$, which is much lower than the melting temperature of the core layer. Diffusion of silicon into the core layer will lower the temperature of the solidus, thereby reducing hightemperature strength [18]. The refinement of the core can accelerate the erosion of $\mathrm{Si}$ and thus deteriorate the sagging resistance. Therefore, it can be concluded that good sagging resistance of $\mathrm{Al}$ clad sheets can be achieved by suppressed erosion of $\mathrm{Si}$ into the core, which can be facilitated by the formation of coarse recrystallized grains during brazing.

The relationship between deformation and grain size is shown in Figure 15. When deformation reaches the critical value $\varepsilon_{\mathfrak{c}}$, mass migration of grain boundaries and recrystallization will occur to give rise to coarse grains. The recrystallized grains tend to be refining continuously as a function of deformation at our testing conditions.

Fully recrystallized microstructures were also confirmed by TEM analysis in all specimens. One example of a TEM image for a specimen fabricated at $410^{\circ} \mathrm{C} / 40 \%$ is given in Figure 16. The EDS analysis was based on eroded areas. The SEM image and EDS mapping of Si for the specimen processed at $410^{\circ} \mathrm{C} / 40 \%$ are given in Figure 17 . As indicated in Figure 17, Si containing eutectic structure can be found within the core that serves as clear evidence of Si penetration 


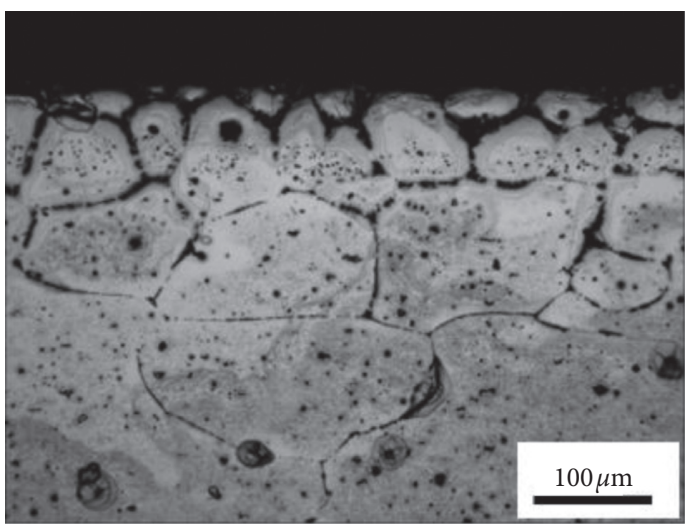

(a)

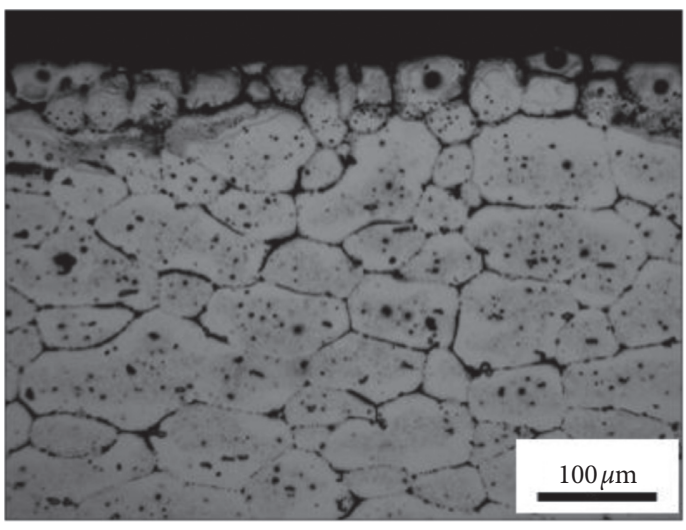

(c)

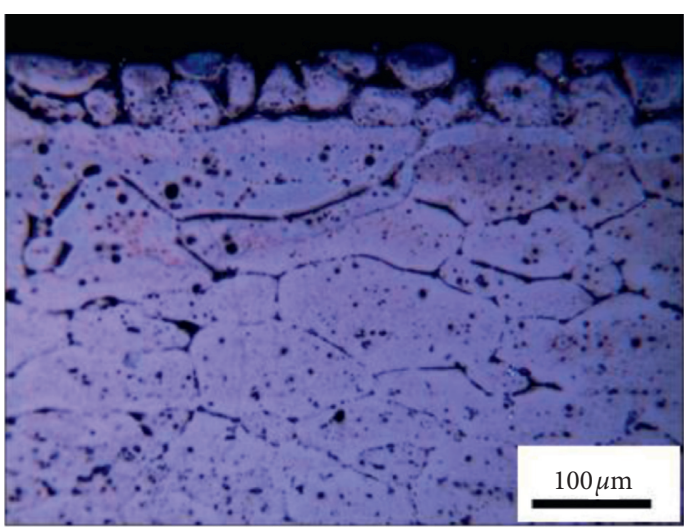

(b)

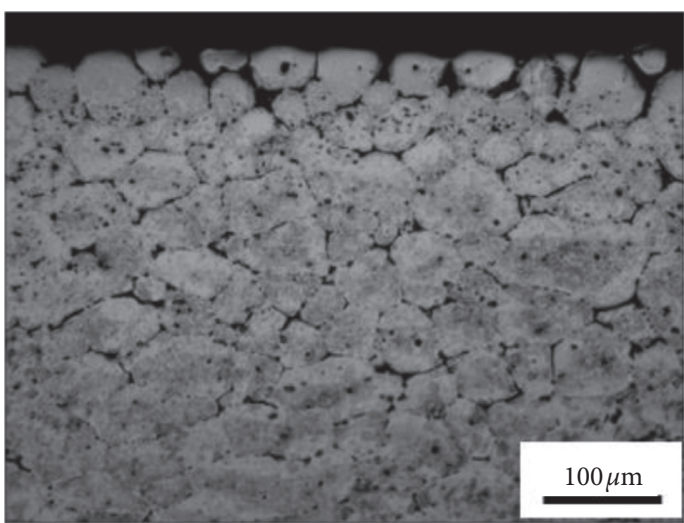

(d)

FiguRE 11: Cross-sectional microstructures of the brazed specimen annealed at $360^{\circ} \mathrm{C}$ and rolled to (a) $10 \%$, (b) $20 \%$, (c) $30 \%$, and (d) $40 \%$.

along grain boundaries. Also, from the TEM photo shown in Figure 16, Si penetration along grain boundaries is clearly revealed.

3.4. Effects of Annealing Temperature on Sagging Value. As shown in Figure 18, the fibrous structure with elongated grains paralleled to rolling direction is clearly observable for Al alloy clad sheets before intermediate annealing. Recrystallization occurred when the annealing temperature was $360^{\circ} \mathrm{C}$. As the temperature increased to $410^{\circ} \mathrm{C}$, the recrystallized grains are slightly smaller than those obtained at $360^{\circ} \mathrm{C}$. The grain size of recrystallized grains has the following relationship with $G$ and $N$ :

$$
d=\text { constant } \times\left[\begin{array}{c}
G \\
\frac{\mathrm{N}}{\mathrm{N}}
\end{array}\right]\left(\frac{1}{4}\right),
$$

where $G$ and $N$ represent nucleation rate and growth rate, respectively. Increasing $N$ and decreasing $G$ can obtain fine recrystallized grains. The activation energy of nucleation of deformed aluminum alloy is much higher. At higher annealing temperature, $N$ increased faster than $G$. Therefore, the recrystallized grain size decreases with annealing temperature.

When annealed at $360^{\circ} \mathrm{C}$ for $2 \mathrm{~h}$ prior to brazing, fibrous structure disappeared and gradually changed into the recrystallized microstructure. Figure 10 shows recrystallized grain structure (as reduction rate increased from 10\% to $40 \%$, and the coarse recrystallized grains formed in the core layer decreased gradually from 156 to $55 \mu \mathrm{m})$. When annealed at $410^{\circ} \mathrm{C}$ for $2 \mathrm{~h}$ before brazing, the number of fine grains and equiaxed grains of the core layer increased. As shown in Figure 11, the average grain size decreased from 120 to $42 \mu \mathrm{m}$ as the reduction rate changed from $10 \%$ to $40 \%$. The subgrain boundary of the brazed sample has disappeared and instead forms a large-angle grain boundary with less area of the grain boundary. Consequently, the diffusion channel of Si has been reduced significantly, so is the tendency of sliding of the movable interface. Their combinative effect is to increase sagging resistance. In the deformation zone, around those coarse intermetallic particles, high annealing temperature could provide more thermal energy for nucleation and growth of recrystallization. Inside coarse grains or at grain boundaries, one may expect to see the formation of a large number of fine recrystallized grains. These fine grains can grow up gradually with time. As a result, the number of fine grains and equiaxed grains kept increasing with smaller average grain size. As the intermediate annealing temperature increased from 360 to $410^{\circ} \mathrm{C}$, the average grain size became smaller and smaller with a larger grain boundary area, thus increasing diffusion channels of $\mathrm{Si}$ and sliding the moving interface. 


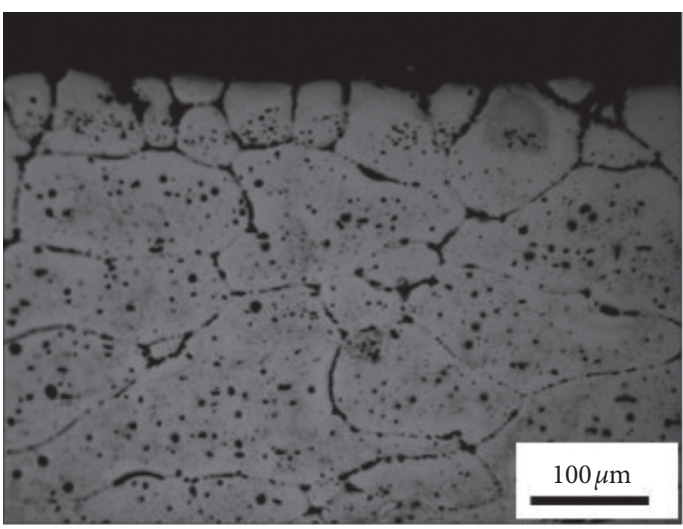

(a)

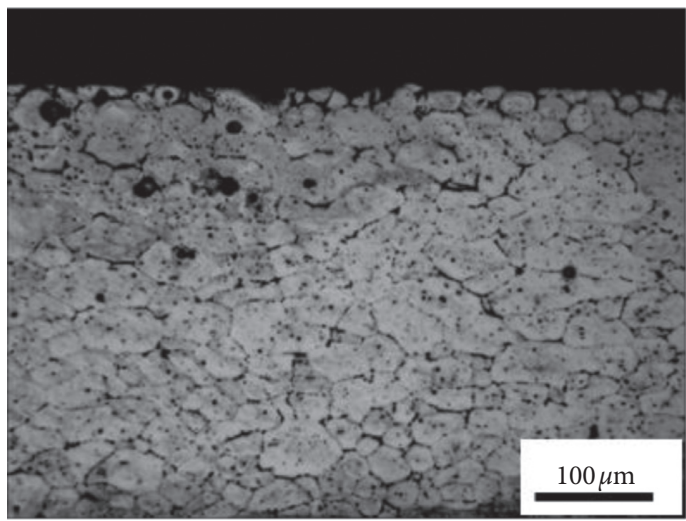

(c)

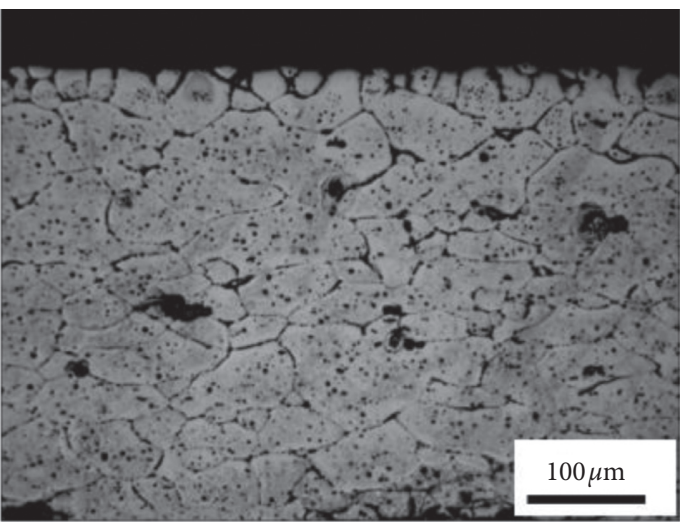

(b)

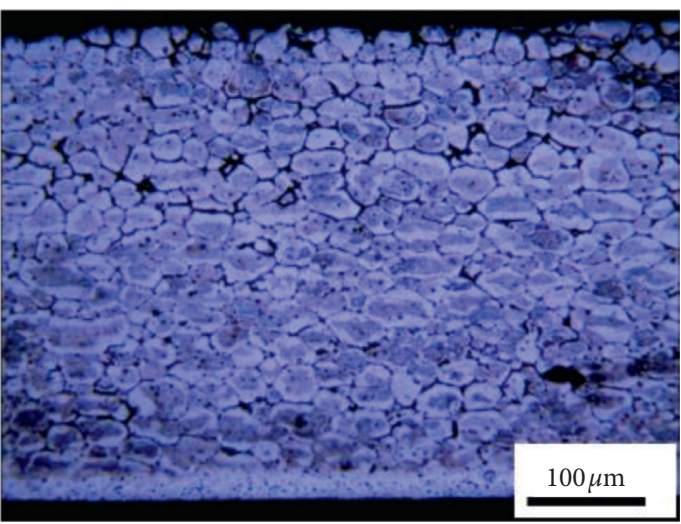

(d)

Figure 12: Cross-sectional microstructures of the brazed specimen annealed at $410^{\circ} \mathrm{C}$ and rolled to (a) $10 \%$, (b) $20 \%$, (c) $30 \%$, and (d) $40 \%$.

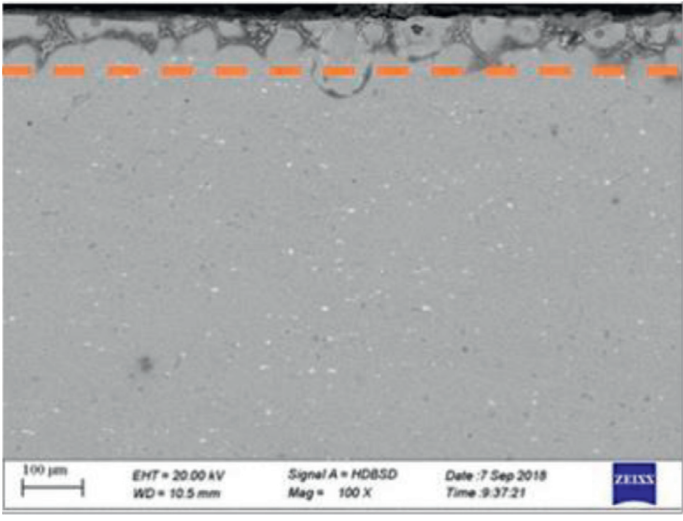

(a)

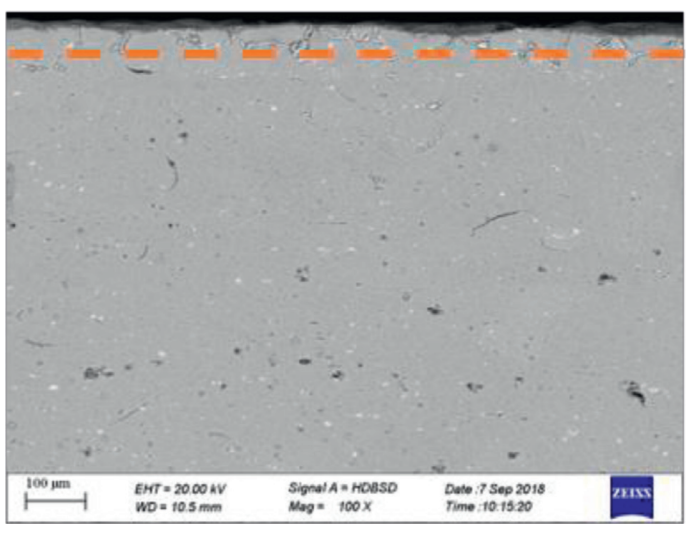

(b)

Figure 13: Microstructures of the $4343 / 3003 / 4343$ clad sheets after brazing: (a) rolled to $40 \%$ and annealed at $360^{\circ} \mathrm{C}$ and (b) rolled to $10 \%$ and annealed at $360^{\circ} \mathrm{C}$.

During the brazing process, with more diffusion channels and easy sliding of moving interface, one would like to see the promotion of the penetration of Si along grain boundary, as shown in Figure 14, whereas a larger erosion depth ratio exhibits inferior sagging resistance. Coarse recrystallized grains with less area of grain boundary reduce diffusion channels of $\mathrm{Si}$ and sliding of moving interface, as shown in
Figure 13, with a smaller erosion depth ratio indicating superior sagging resistance. Therefore, the sagging resistance performance of $360^{\circ} \mathrm{C}$ intermediate annealing is better than that of $410^{\circ} \mathrm{C}$.

During the brazing process, the core layer formed with much finer $\mathrm{Al}(\mathrm{Mn}, \mathrm{Fe}) \mathrm{Si}$ precipitated particles [19]. Therefore, the different number densities of Al-Si-Mn-Fe or 


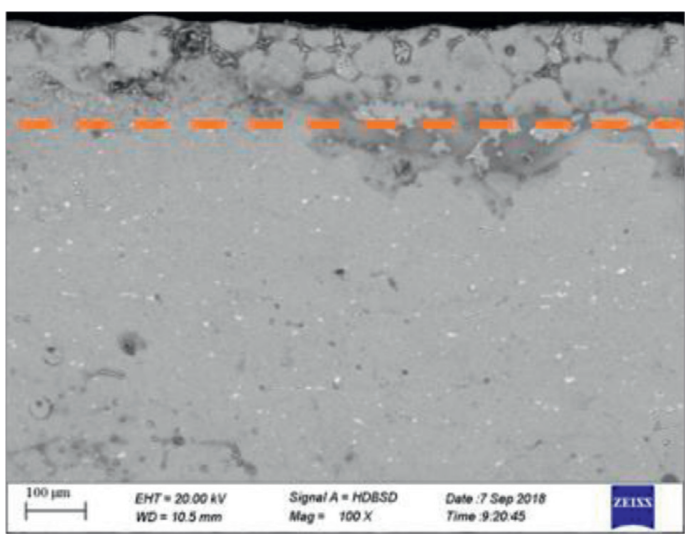

(a)

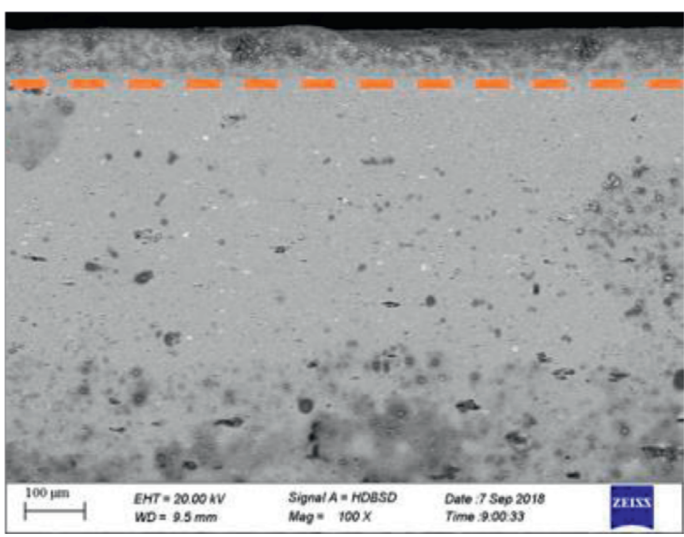

(b)

Figure 14: Microstructures of the $4343 / 3003 / 4343$ clad sheets after brazing: (a) rolled to $40 \%$ and annealed at $410^{\circ} \mathrm{C}$ and (b) rolled to $10 \%$ and annealed at $410^{\circ} \mathrm{C}$.

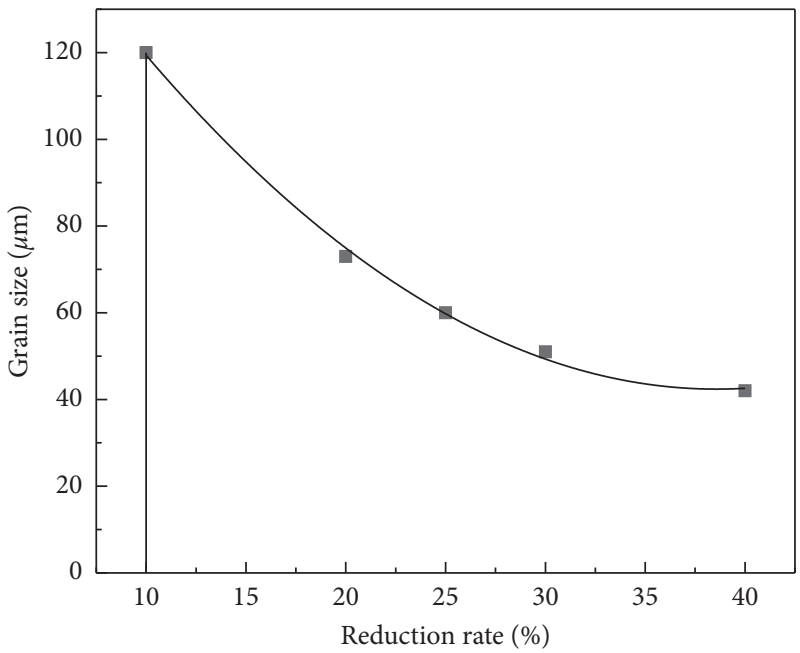

Figure 15: Effect of reduction rate on the grain size of the sample brazed at $410^{\circ} \mathrm{C}$.

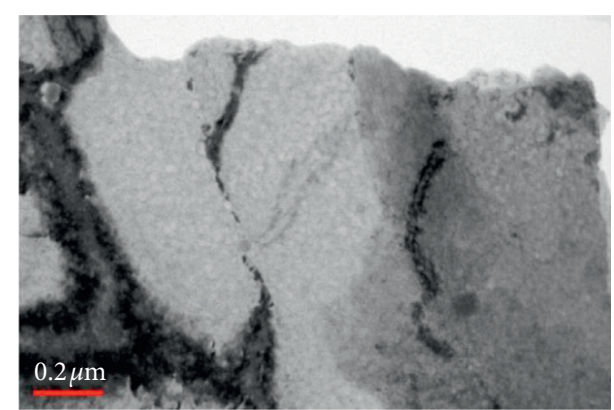

FIGURE 16: TEM image for the brazed specimen.

$\mathrm{Al}-\mathrm{Si}-\mathrm{Mg}-\mathrm{Cu}$ particles formed in the core layer of the brazing plate will also affect the sagging resistance. The expression for the pinning force of Zener is as follows:

$$
P_{Z}=\frac{3 F_{v} \gamma_{b}}{d}
$$

where $F_{v}$ represents volume fraction of second phase particle; $\gamma_{b}$ represents the grain boundary energy; and $d$ represents the second phase particle diameter. The theory of particle-stimulated nucleation pointed out that the pinning of dislocation and subgrain boundary is greatly weakened when the grain size is relatively larger that makes recrystallization easy and can be used as a nucleation substrate for recrystallization to promote nucleation. When the particles are relatively smaller, they primarily play the role of pinning dislocations and subgrain boundaries, hindering the formation of recrystallized cores, causing difficulty in recrystallization, and thus forming coarse grain structure [20,21]. These precipitated particles have high density and relatively small size; the small size precipitated particles will have an obvious pinning effect on dislocations. The pinning force per unit area is shown in formula (1), so the grain boundary slip will become very difficult. Dislocation rearrangement is hindered at a high temperature, the formation of recrystallized nuclei is inhibited, and the grain structure becomes 


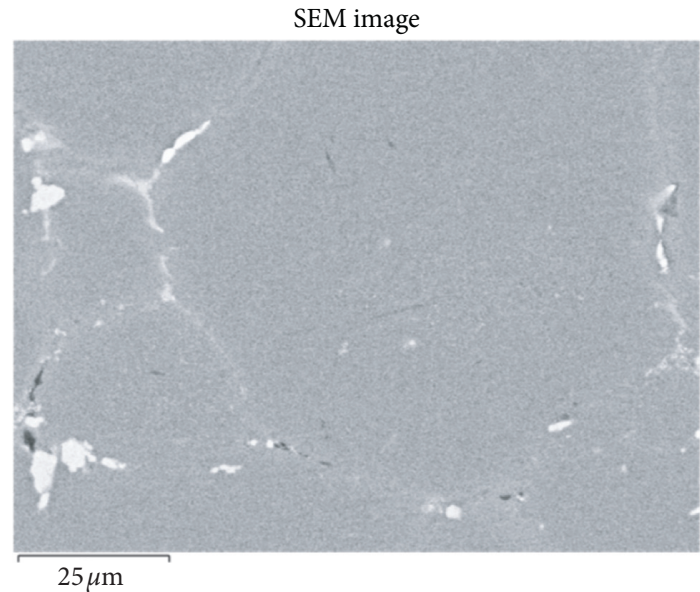

(a)

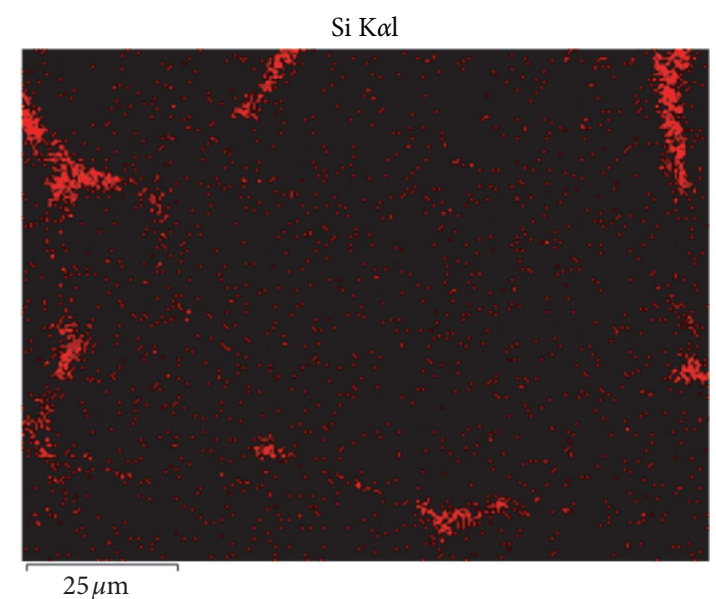

(b)

FIGURE 17: SEM image and EDS map of Si for the brazed specimen.

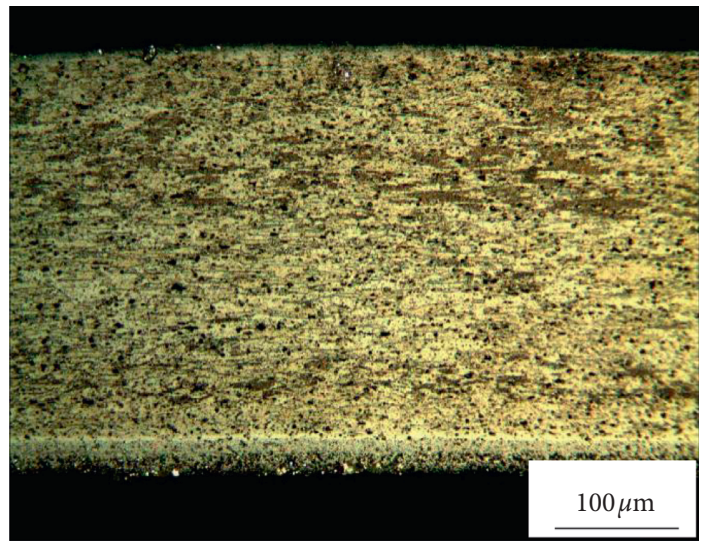

FIGURE 18: Microstructure of the 4343/3003/6111/3003 alloy specimen before annealing

coarse. To improve the sagging resistance of brazed aluminum foil, it is necessary to control and reduce the penetration of molten filler into the core alloy during brazing. However, the formation of coarse grains in core alloy hinders the penetration of silicon, which is beneficial to improve the sagging resistance.

When specimens are processed at the same cold rolling reduction rates, the sagging resistance for those annealed at $360^{\circ} \mathrm{C}$ is superior to those annealed at $410^{\circ} \mathrm{C}$, as indicated in Figure 9. In this case, the grain sizes for those annealed at both temperatures show difference. This phenomenon may be resulted from the difference in the number density of Al$\mathrm{Si}-\mathrm{Mn}-\mathrm{Fe}$ - or Al-Si-Mg-Cu-based particles formed in the core. When annealed at $360^{\circ} \mathrm{C}$, the particle number density is clearly higher than those annealed at $410^{\circ} \mathrm{C}$ when the same reduction rate is employed as indicated in (Figures 19 and 20). Those precipitates could cause an increase in the strength of the $\mathrm{Al}$ clad sheets and thus improve their sagging resistance.

Based on our work, we could make the following conclusions:
(1) The strength of hot-rolled four-layered aluminum alloy clad sheets changes slightly when it is annealed at a temperature above $360^{\circ} \mathrm{C}$ with maximal elongation appeared at $410^{\circ} \mathrm{C}$.

(2) As the reduction rate increased from $10 \%$ to $40 \%$, the sagging distance of the hot-rolled (4343/3003/6111/ 3003) clad sheet increased from 3 to $15.7 \mathrm{~mm}$ for annealed specimens at $360^{\circ} \mathrm{C}$. Once the specimen is annealed at $410^{\circ} \mathrm{C}$, the sagging distance is increased from 3.1 to $20.8 \mathrm{~mm}$.

(3) Formation of coarse recrystallized grain structure can suppress erosion of $\mathrm{Si}$ into the core during brazing, which results in excellent sagging resistance. Excellent sagging resistance is the result of suppressed erosion of Si into the core. By contrast, deteriorated sagging resistance is caused by the formation of fine recrystallized grains in the core, which promotes Si penetration along grain boundaries.

(4) At the same reduction rate, the sagging resistance of the sample annealed at $360^{\circ} \mathrm{C}$ is superior to that 


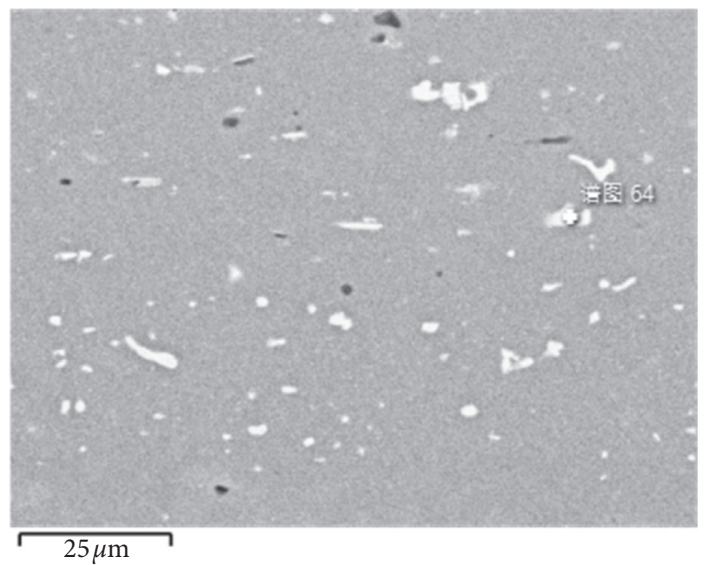

(a)

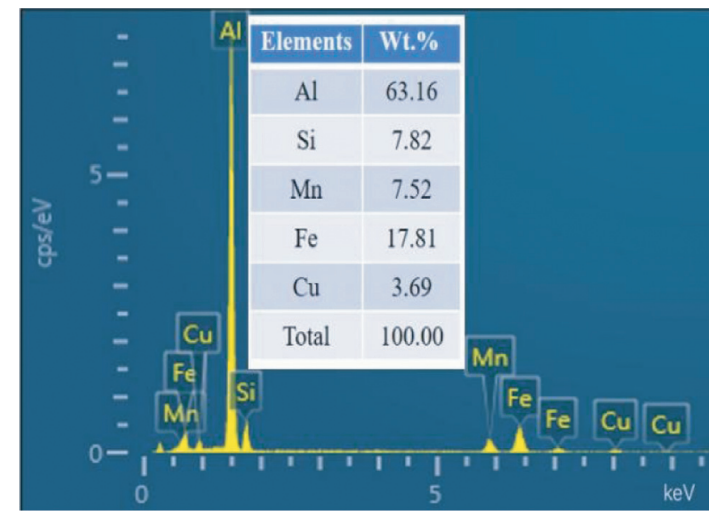

(b)

Figure 19: Typical SEM images of the brazed specimen rolled to $30 \%$ and annealed at $360^{\circ} \mathrm{C}$.

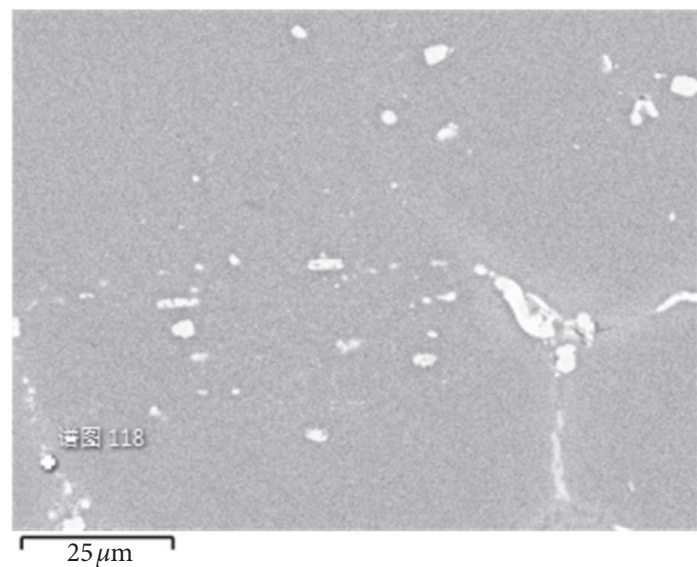

(a)

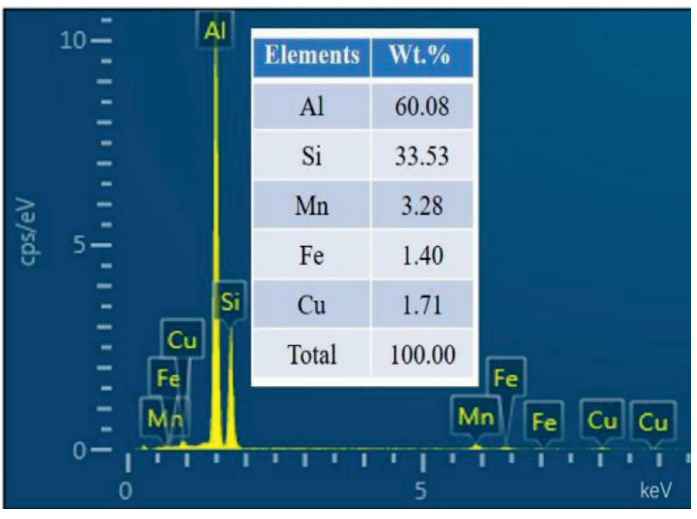

(b)

Figure 20: Typical SEM images of the brazed specimen rolled to $30 \%$ and annealed at $410^{\circ} \mathrm{C}$.

annealed at $410^{\circ} \mathrm{C}$. There are two reasons: the first one is that the average grain size of those samples annealed at $360^{\circ} \mathrm{C}$ was larger than those annealed at $410^{\circ} \mathrm{C}$ and another reason is that the formation of small size precipitates at $360^{\circ} \mathrm{C}$ causing an increase in strength.

\section{Data Availability}

The data used to support the findings of the study are available from the corresponding author upon request (zhoulina.0401@163.com).

\section{Conflicts of Interest}

The authors declare that there are no conflicts of interest regarding the publication of this paper.

\section{Acknowledgments}

This research was funded by the National Natural Science Foundation of China (grant no. 51705539). All authors thank Zheng Feng for help in checking the manuscript before submission.

\section{References}

[1] M. S. Rad, Z. Ahmad, and A. Alias, "Computational approach in formulating mechanical characteristics of 3D star honeycomb auxetic structure," Advances in Materials Science and Engineering, vol. 2015, Article ID 650769, , 2015.

[2] S. H. Lee, J. S. Yoon, M. S. Kim, and D. Jung, "Effects of cold rolling parameters on sagging behavior for three layer $\mathrm{Al}-\mathrm{Si}$ / $\mathrm{Al}-\mathrm{Mn}(\mathrm{Zn}) / \mathrm{Al}-\mathrm{Si}$ brazing sheets," Metals and Materials International, vol. 8, no. 3, pp. 227-232, 2002.

[3] S. H. Lee, M. S. Kim, D.-S. Jung, J. W. Han, and B. D. You, "Fabrication and sagging behavior of three-layer Al-Si/Al$\mathrm{Mn}-\mathrm{Zn} / \mathrm{Al}-\mathrm{Si}$ clad sheets for automotive heat exchanger," Materials Science Forum, vol. 439, pp. 221-226, 2003.

[4] J. S. Yoon, S. H. Lee, and M. S. Kim, "Sagging resistance of cold rolled aluminum 4343/3N03/4343 clad sheet," Journal of Materials Science Letters, vol. 20, no. 3, pp. 229-232, 2001.

[5] U. Trdan and J. Grum, "Investigation of corrosion behaviour of aluminium alloy subjected to laser shock peening without a 
protective coating," Advances in Materials Science and Engineering, vol. 2015, Article ID 705306, , 2015.

[6] Y. Tu, Z. Tong, and J. Jiang, "Effect of microstructure on diffusional solidification of 4343/3005/4343 multi-layer aluminum brazing sheet," Metallurgical and Materials Transactions A, vol. 44, no. 4, pp. 1760-1766, 2013.

[7] J. S. Yoon, S. H. Lee, and M. S. Kim, "Fabrication and brazeability of a three-layer 4343/3003/4343 aluminum clad sheet by rolling," Journal of Materials Processing Technology, vol. 111, no. 1-3, pp. 85-89, 2001.

[8] J. Qin, S.-B. Kang, and J.-H. Cho, "Sagging mechanisms in the brazing of aluminum heat exchangers," Scripta Materialia, vol. 68 , no. 12, pp. 941-944, 2013.

[9] Y.-Y. Zhao, Z.-Y. Zhang, L. Jin, and J. Dong, "Effects of annealing process on sagging resistance of cold-rolled threelayer Al alloy clad sheets," Transactions of Nonferrous Metals Society of China, vol. 26, no. 10, pp. 2542-2551, 2016.

[10] C.-L. Tang, Q.-P. Xu, X.-F. Guo et al., "Sagging mechanisms of three-layer aluminum clad foils used in the heat exchanger in the brazing process," Journal of Materials Engineering and Performance, vol. 27, no. 9, pp. 4846-4854, 2018.

[11] C. Liu, X. Xue, X. Chen et al., "Effect of microstructural evolution on sagging behavior of cold-rolled aluminum foil during the brazing thermal cycle," Journal of Materials Engineering and Performance, vol. 26, no. 11, pp. 5563-5570, 2017.

[12] W. Kimberley, "Lighter weight leads to fuel savings," Review of Automotive Engineering, vol. 29, pp. 30-31, 2004.

[13] J. S. Ryu, M. S. Kim, and D. S. Jung, "Brazeability of cold rolled three layer $\mathrm{Al}-7.5 \mathrm{Si} / \mathrm{Al}-1.2 \mathrm{Mn}-2 \mathrm{Zn}-(0.04-1.0) \mathrm{Si} / \mathrm{Al}-7.5 \mathrm{Si}$ (wt.\%) clad sheets," Journal of Materials Processing Technology, vol. 130-131, no. SI, 2002.

[14] W. S. Miller, L. Zhuang, J. Bottema et al., "Recent development in aluminium alloys for the automotive industry," Materials Science and Engineering: A, vol. 280, no. 1, pp. 37-49, 2000.

[15] S. J. Noh, M. S. Kim, D. Jung, J. W. Han, and B. D. You, "Effects of Si content and cold rolling condition on brazeability of Al-Mn-Zn alloy core brazing sheet," Materials Science Forum, vol. 486-487, pp. 415-419, 2005.

[16] N. Sun, B. R. Patterson, P. Jaakko, J. P. Suni, and R. D. Doherty, "Effect of heating rate on recry- stallization of twin roll cast aluminum," Metallurgical and Materials Transactions A, vol. 39A, no. 1, pp. 156-170, 2008.

[17] W. C. Liu and B. Radhakrishnan, "Recrystallization behavior of a supersaturated Al-Mn alloy," Materials Letters, vol. 64, no. 16, pp. 1829-1832, 2010.

[18] T. Carlberg, M. Jaradeh, and H. Kamgou Kamaga, "Solidification studies of automotive heat exchanger materials," JOM, vol. 58, no. 11, pp. 56-61, 2006.

[19] M. Nylén, U. Gustavsson, W. B. Hutchinson, and Å. Karlsson, "The mechanism of braze metal penetration by migration of liquid films in aluminium," Materials Science Forum, vol. 331337, pp. 1737-1742, 2000.

[20] M. Aghaie-Khafri and R. Mahmudi, "Optimizing homogenization parameters for better stretch formability in an AlMn-Mg alloy sheet," Materials Science and Engineering A, vol. 339, no. 1-2, pp. 173-180, 2005.

[21] Y. J. Li and L. Arnberg, "Evolution of eutectic intermetallic particles in DC-cast AA3003 alloy during heating and homogenization," Materials Science and Engineering A, vol. 347, no. $1-2$, pp. $130-135,2003$. 